\title{
Quantitative estimation and spatial reconstruction of urban and rural construction land in Jiangsu Province, 1820-1985
}

\author{
XIE Jinyuan", "JIN Xiaobin ${ }^{1,2}$, LIN Yinan ${ }^{1}$, CHENG Yinong ${ }^{3}$, YANG Xuhong ${ }^{1}$, \\ BAI Qing ${ }^{2}$, ZHOU Yinkang ${ }^{1,2}$ \\ 1. School of Geographic and Oceanographic Sciences, Nanjing University, Nanjing 210023, China; \\ 2. Natural Resources Research Center of Nanjing University, Nanjing 210023, China; \\ 3. School of History and Archives, Yunnan University, Kunming 650091, China
}

\begin{abstract}
Land cover is the most evident landscape signal to characterize the influence of human activities on terrestrial ecosystems. Since the industrial revolution, the expansion of construction land has profoundly changed the status of land use coverage and changes. This study is proposed to reconstruct the spatial pattern of construction land (urban construction land and rural settlement land) for five historical periods over the past 200 years in Jiangsu Province with $200 \mathrm{~m} \times 200 \mathrm{~m}$ grids on the basis of quantitative estimation. Urban construction land is estimated based on data about city walls, four gates along walls, and other socio-economic factors. Rural settlement land is calculated based on the rural population and per capita housing allowance. The spatial pattern of historical construction land is simulated based on the distribution of modern construction land in 1985 with a quantitative-boundarysuitability control method and thorough consideration over connectivity of different land use types. The study concludes that: (1) the amount of construction land in Jiangsu Province is estimated at $963.46 \mathrm{~km}^{2}$ in $1820,1043.46 \mathrm{~km}^{2}$ in $1911,1672.40 \mathrm{~km}^{2}$ in $1936,1980.34 \mathrm{~km}^{2}$ in 1952 and $10,687.20 \mathrm{~km}^{2}$ in 1985; and (2) the spatial distribution of construction land features the great proclivity to water bodies and main roads and the strong polarization of existent residence. The results are verified directly and indirectly by applying the trend verification of construction land changes and patterns, the correlation analysis between rural settlement land and local arable land, and quantitative accuracy test of the reconstructed construction land to actual historical survey maps covering four sample regions in 1936.
\end{abstract}

Keywords: construction land; reconstruction; grid; past 200 years; Jiangsu

\section{Introduction}

Global climate change and human activities act as the dual stressors which drastically change the Earth's landscapes and increase the fragility of the Earth's ecosystem. Western

Received: 2017-03-04 Accepted: 2017-03-30

Foundation: National Natural Science Foundation of China, No.41340016, No.41671082

Author: Xie Jinyuan (1991-), MS Candidate, specialized in land resource and management. E-mail: jinyuanxie_nju@163.com

"Corresponding author: Jin Xiaobin (1974-), specialized in land use and land planning. E-mail: jinxb@nju.edu.cn 
industrial revolution, rapid development of science and technology, substantial increase of productivity, population growth, and the expansion of modern cities all lead to the remarkable phenomenon that construction land has become one of the dominant land use types (Bao and Gao, 2016; Saunders, 2012; Yang et al., 2016). Construction land affects the global and regional climate by changing the nature of the underlying surface and intensifying the combustion of fossil fuels (Gu et al., 2011; Yan et al., 2016).

Current researches on the temporal and/or spatial dimensions of construction land changes mainly focus on central cities and employ a comprehensive analysis based on multiple data sources such as historical documents, historical maps, and modern remote sensing images. For example, Liu et al. (2010) collected historical land statistical data and modern remote sensing data to rebuild the urban land statistics from 1700 to 2005 in China while taking population data into consideration; Tian et al. (2014) used remote sensing imagery and historical statistical records as data sources and amended land use data from 1880 to 2010 in India; He et al. (2002) estimated urban built-up areas in 18 provinces in 1820 by using city wall perimeter data recorded in historical records in the Qing Dynasty; Fang et al. (2002), Yin et al. (2013), Ji et al. (2009) and Li et al. (2014) explored the urban changes of Beijing, Shanghai, Guangzhou, and Guiyang respectively in the centennial scale based on historical documents, historical maps and modern remote sensing imagery.

There are two major methods of spatial reconstruction: the top-down "static allocation" and the bottom-up "dynamic evolution". "Static allocation" is generally accompanied with variables such as historical population density, modern land use pattern, or land suitability. Tian et al. (2014) allocated historical land use types based on the modern population density and historical population data. Liu et al. (2010) framed a historical land use pattern based on historical statistics and modern land use distribution as interpreted from remote sensing imagery. Pan et al. (2015) and Lin et al. (2015) selected the topography, distances from rivers, and other natural characteristics as well as socio-economic factors to structure land suitability models as base maps to allocate historical construction land. "Dynamic evolution" simulates historical land use patterns through successive loop iterations upon grids that incorporate indicators and rules representing human land use behaviors and artificial intelligence algorithms. Schaldach et al. (2011) conducted a land suitability analysis based on factors such as topographic slopes, the road infrastructure, and protected areas by using population change data as the main trigger. Population for each urban and rural grid was then allocated according to population density and estimated land suitability. Whenever the population density for a grid was calculated greater than the set (default) value, the preset land use type was then switched to the other. Ray et al. (2010) progressively rebuilt the construction land in the Muskegen River Basin in Michigan based on land use and transformation characteristics identified from different periods of land use remote sensing data by applying the artificial neural network algorithm. Bai et al. (2007) reconstructed a spatial pattern of land use based on modern topographical maps and historical aerial photographs. Light condition, temperature and water resource were defined as independent variables while the type of historical land use was the dependent variable. The logistic binary regression model was applied to determine the transition probability.

Although these researches have provided some tentative perspectives to reconstruct historical construction land, some aspects in this research domain still remain in an exploratory 
phase. These aspects include but not limited to the integrity of objects of land reconstruction, identification and quantification of key factors, and refinement of the spatial resolution. According to the typicality of historical background and accessibility of historical data, this study selected five time intersects in the last 200 years during which China was under three different regimes: the year 1820 in the middle of the Qing Dynasty, the year 1911 in the end of the Qing Dynasty and early stages of the Republic of China, the year 1936 in the middle of the Republic of China, the year 1952 in the early stages of the People's Republic of China, and the year 1985 in the early stages of China's Reform and Opening up. While construction land (including urban construction land and rural settlement land) is proposed as the study object and the modern geographic coverage of Jiangsu Province is set to be the research scope, this study aims to provide a fresh perspective to rebuild the spatial and temporal pattern for historical construction land with contemporary natural resources and environmental data, historical documents, concerns over urbanization and the human-land relationship. A desired verification method is also provided and discussed. This study attempts to provide methodological references and data support for the larger scale and longer time span reconstruction of construction land or multiple (all) land use types.

\section{Characteristics of construction land changes and reconstruction perspectives}

\subsection{Characteristics of construction land changes}

Most contemporary construction land is the outcome of the evolution of settlements. Settlements were initially to meet the basic needs of human habitation and progressively developed into larger plots to accommodate economic development, political evolution, cultural cultivation, and/or life assistance, and/or as a response to defense requirements, and/or religious propaganda (Ma et al., 2016; Zhou et al., 2013). Spatially, settlements generally evolve from "points" to "axes" and then to "surfaces". Some "points" become regional centers with strong and dense aggregations, which influence and stimulate the development of surrounding areas through the "diffusion effect". This process generally begins with the traffic vicinity, and forms a central area along traffic lines ("axis"). An overlapping of "axis" and the combination of "axis" and "point" result in a bigger "expansion effect" toward the "surface", which forms denser and more modern regional traffic networks and urban structures (Hu, 1994).

In this study, the urban construction land includes construction land in cities and towns. Construction land labeling with "city" refers to the land at and above the county level while used for residence, worship, roads, markets, defense, storage, management, and other purposes. Construction land identified as "town" refers to the land below the county level with relatively concentrated economy and population while mainly used for residence, commerce, warehousing, and production.

Historically, urban development was slow in China. Cities and towns were generally small in scale and mostly with explicit boundaries (walls and four gates ${ }^{1}$ ). The handicraft industry, markets, residences, government offices, and temples, were usually distributed in

\footnotetext{
${ }^{1}$ Four-gates refer to the handicraft industry and commercial shops that were distributed in the center of a town, and may be considered a city street or street market.
} 
the central urban area. It is common that a certain amount of agricultural land or open space was present between the wall and the central area. With the increase of urban population, the urban land expanded by "filling in" the space within the city walls until the urban space was "saturated". Subsequently, the urban land would break through the limitation of the city walls.

In the early modern period, the sprout of capitalism intensified the aggregation of various elements in urban space, pushed the expansion of urban scales and the births of new industrial cities and towns, and stimulated the diffusion of urban construction land toward its periphery. Later, urban construction land further expanded to surrounding suburbs associated with the rapid growth of industry and population. In some cases, the cities rapidly expanded to reach the far suburbs. The urban structure tended to develop in a network style and the expansion of urban construction land progressed from the "point-axis" style to a "point-axissurface" style (Xu et al., 2009).

Rural settlement land refers to the land outside the urban area but not used for agricultural production. It includes farmers' residential areas, courtyards, and drying areas as well as land for village infrastructure and public facilities (Hu et al., 2007; Jin et al., 2016).

Historically, the development of most rural settlements was slow and many rural settlements' centers had remained stable for a long time (Jin, 1988; Yang et al., 2016). In the early modern period, the development of agricultural economy was lagging because of little advances in agricultural technologies and the deficiency of policy incentives. The development and the renovation of rural housing were also slow. Most houses were built along the main traffic routes in villages. The rural settlement land typically expanded in a "point-axis" style. With the expansion of the central area, small-scale and scattered settlements nearby were attracted or progressively merged into large settlements. In recent decades (especially after the 1980s), with the improvement of agricultural production conditions, the rapid development of the agricultural economy, and the substantial improvement of living conditions, the building of new houses and renovation of existing houses have become a popular trend. Rural settlement land expands typically in a spreading style, i.e., often occupying surrounding agricultural land directly.

\subsection{Perspectives on reconstructing historical construction land}

In contrast to modern construction land data, the availability of historical data is affected by the scope, integrity, and accessibility of historical documents. In general, historical construction land data can be obtained by applying any of three methods: (1) reasonable amendments according to the credibility of original data such as historical documents, modern statistics, and other historical resources; (2) estimation with the historical population, structure, per capita land use, and other indirect indictors; (3) calculation with substitute indicators (such as city wall perimeter and shape) related to land use except population data.

This study uses the spatial distribution of construction land in 1985 as the basis to derive the spatial pattern of construction land in four typical historical intersects $(1820,1911,1936$, and 1952) by employing quantitative-boundary-suitability control methods with the connectivity of land use, the different expansion processes and characteristics of urban land and rural settlements during the study period. Figure 1 illustrates the methodology applied in this study. 


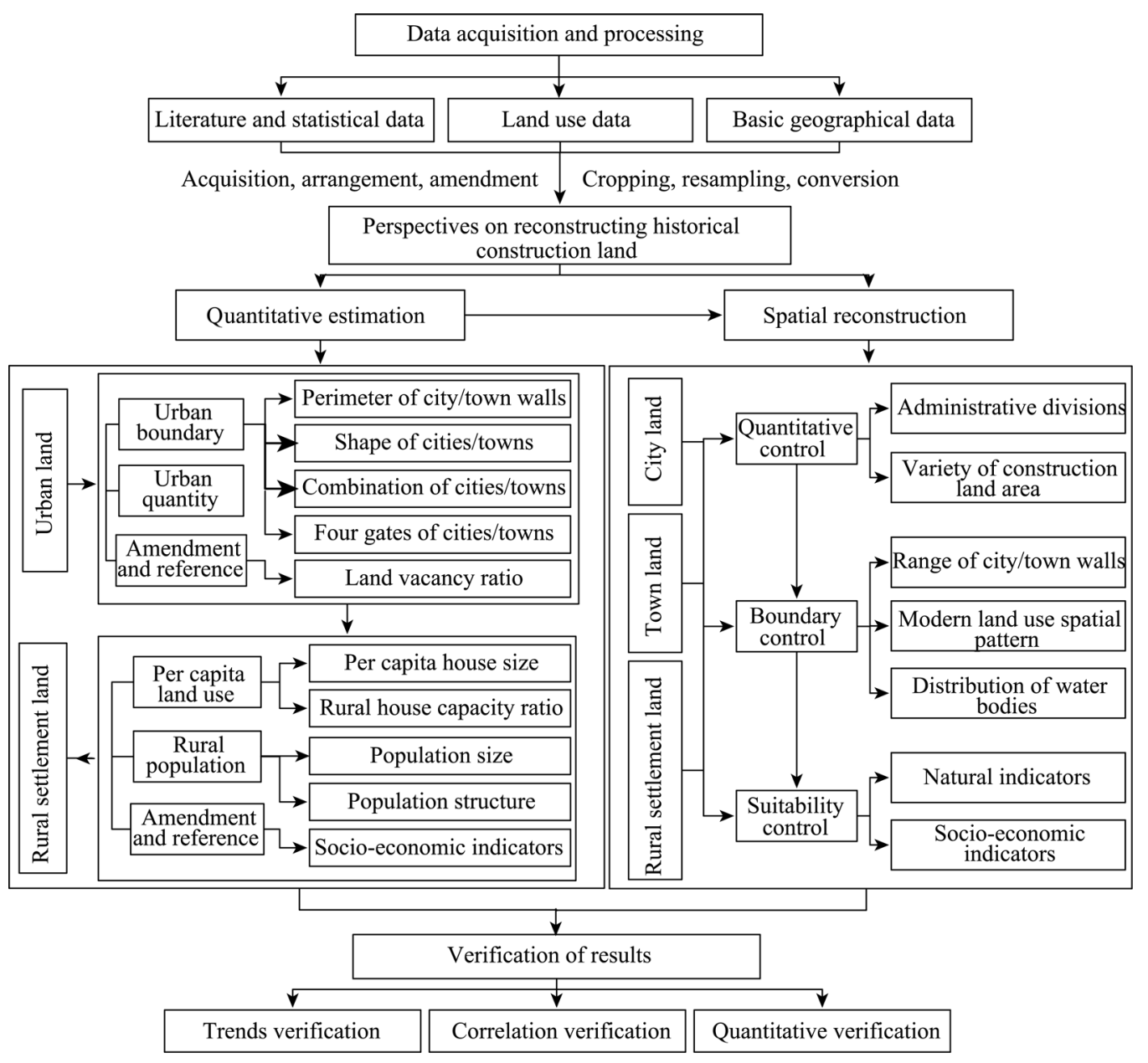

Figure 1 Technical route of the study

"Quantitative estimation" has been mainly conducted with the examination of historical documents and the acquisition, arrangement, and amendment of related literatures.

(1) Urban land

For the year 1820, the area of a city/town was determined mainly based on data such as the perimeter of city/town walls, the shape of a city/town, the combination of cities/towns, and the four gates surrounding a city/town. With all cities and towns, the amount of urban land can be obtained.

For the other three time intersects of 1911, 1936 and 1952, the amount of urban land was estimated mainly based on per capita land use level with delicate calibration with corresponding socio-economic data and the population size and structure. The amount of urban construction land was then further allocated to cities and towns according to the structure of urban population.

(2) Rural settlement land

In rural areas, per capita settlement land has been inferred from per capita house size and the average house capacity ratio along with the proportion of public construction land. Then the amount of rural settlement land can be calculated based on per capita settlement land and 
the corresponding rural population for any of our four proposed time intersects.

The spatial grids of historical construction land in Jiangsu Province therefore can be rebuilt with $200 \mathrm{~m} \times 200 \mathrm{~m}$ resolution in association with historical records about city walls, construction land suitability evaluation and the connectivity of different land use types.

The results then can be verified in terms of process analysis, correlation analysis and spatial pattern comparison to illustrate the effectiveness of our research outcomes.

\section{Research area and data sources}

\subsection{Research area}

The defined research area is Jiangsu Province with the modern administrative boundary. It is located at $116^{\circ} 18^{\prime}-121^{\circ} 57^{\prime} \mathrm{E}$ and $30^{\circ} 45^{\prime}-35^{\circ} 20^{\prime} \mathrm{N}$. Its climate is in a transitional zone from semi-tropical to warm temperate. It is of a flat and low terrain with an overall topography of high in the northern and southern parts, low in the central, declining from west to east. Plains are the typical landforms in the area, taking about $68.81 \%$ of the total land. It possesses several conjoining rivers and dense water networks. $16.86 \%$ of the total land is occupied by water bodies with a coastline of $954 \mathrm{~km}$ in length.

Jiangsu Province has been a traditional agricultural production region for centuries due to its mild temperature, great moisture conditions, plain territories, thick soil layers, fertile soil conditions, abundant water bodies, etc. Meanwhile, along with the development of the handicraft industry, urban commodity economy, and the cultural advancement, it has become one of the most developed regions in China since the Ming Dynasty.

Jiangsu Province was officially set up in 1667 (the 6th year of Emperor Kangxi's reign in Qing Dynasty) and came into its current shape by 1767 (Fu, 2009). Although severe changes occurred to its administrative boundary during our study period, there was little change in terms of administration structure. From the mid-Qing Dynasty (1820) to early years of the Republic (1911), there were seven Fu (cities), four Zhou (cities) and one Ting (city). Specifically, seven units of "Fu" refer to Jiangning, Suzhou, Changzhou, Zhenjiang, Yangzhou, Huai'an and Xuzhou; four units of "Zhou” include Tongzhou, Haizhou, Sizhou and Taicang, and one unit of "Ting" is Haimen. In 1936, an administrative inspection district system was installed. Jiangsu was divided into a number of districts with subordinate counties, i.e. Jiangning, Liyang, Wuxi, Nantong, Jiangdu, Yancheng, Huaiyin, Donghai, Tongshan and Sixian. In 1983, the contemporary administrative system of cities with subordinate counties was put in place, including 11 cities: Nanjing, Wuxi, Xuzhou, Changzhou, Suzhou, Nantong, Lianyungang, Huaiyin, Yancheng, Yangzhou and Zhenjiang. Figure 2 shows historical maps of the administrative structure in Jiangsu Province for these typical historical time intersects.

\subsection{Data sources}

Data involved in this study are of three types: literature and statistical data, land use data, and basic geographical data. Specifically,

(1) Literature and statistical data include data for urban and rural settlements, and population, socio-economic data. These data are primarily used for the quantitative control of the construction land. 

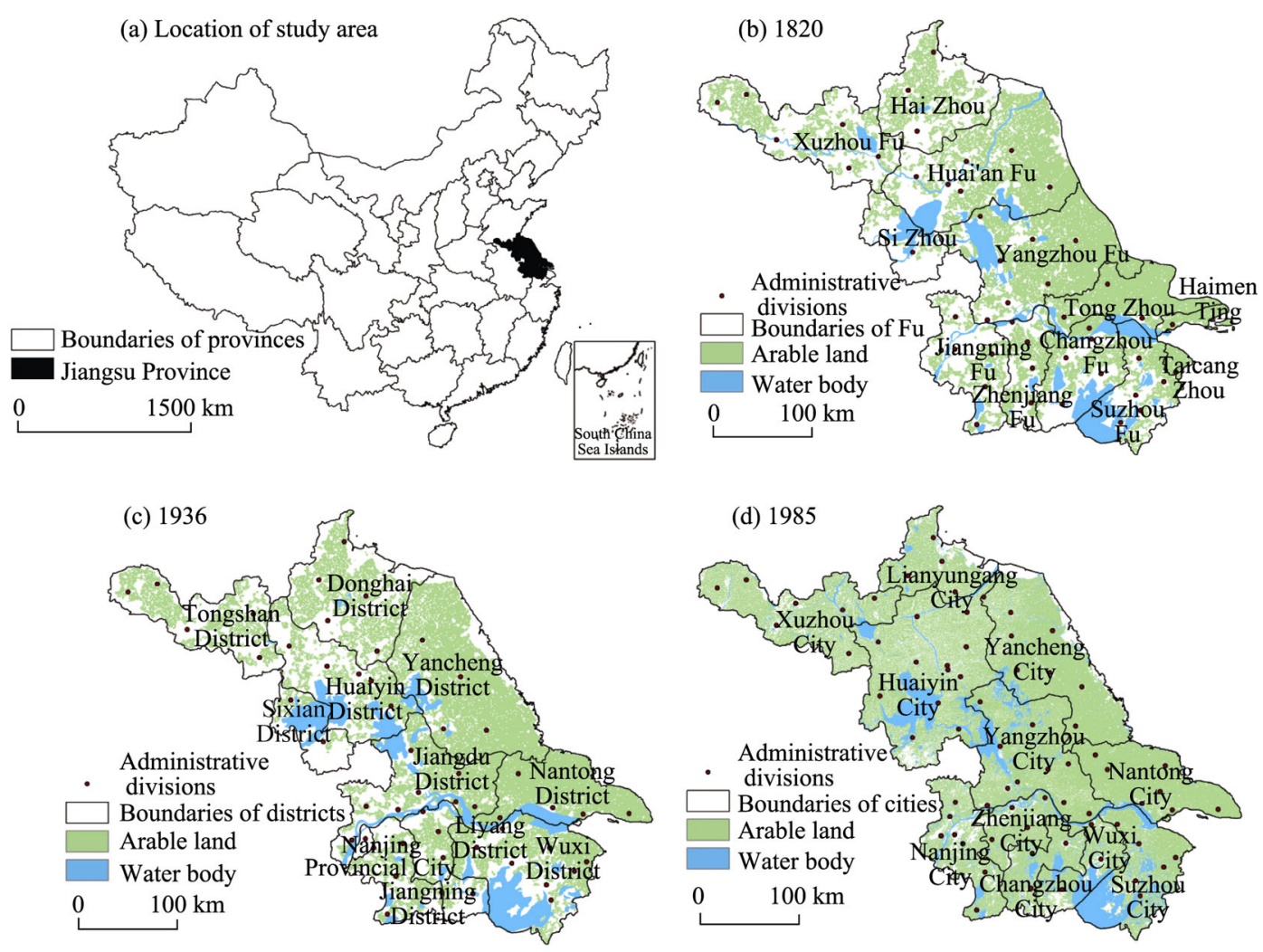

Figure 2 Changes of administrative division and land use of research area in typical periods (1. Arable land data derived from Yang et al. (2015); 2. Water areas data drawn from Historical Geographic Information System)

\subsubsection{Urban construction land data}

Perimeters of city/town walls in 1820 are drawn from Jiaqing Rebuilt Chi Unification. The administrative system in Qing Dynasty is from Draft of History of Qing Dynasty (Zhao, 1976) and Geography History Table of Qing Dynasty (Zhao, 1941). Per capita urban construction land around the founding of the People's Republic is from Urban Historical Geography of Jiangsu (JGI, 1982). Data about four gates along the city walls in the Qing Dynasty is derived from Fan (1990).

\subsubsection{Rural settlement data}

Per capita rural house size in 1933 is from Bo (1941). The rural house capacity ratio is drawn from Song et al. (2008) and Lin et al. (2015).

\subsubsection{Population data}

City $(\mathrm{Fu})$ population (household) data in 1820, 1911, 1936 and 1952, are adapted from Cao (2002), Population Geography Information System (http://cpgis.fudan.edu.cn/cpgis/default. asp), and Fifty Years of Jiangsu Province (EB, 1999). The population structure data is based on Wang (1984) and Fifty Years of Rural Economy of Jiangsu Province (EB, 2000).

\subsubsection{Socio-economic data}

Associations and chamber of commerce data at the end of the Qing Dynasty and early years 
of the Republic are drawn from Wang (1984). Rural agricultural company data for the end of the Qing Dynasty and early years of the Republic are from Archives Compilation of History of Republic of China (Third Series Agriculture and Commerce) (SHAC, 1998a). The gross value of urban industrial products in 1930 is from Archives Compilation of History of Republic of China (Fifth Series Finance and Economy) (SHAC, 1998b). Rural cooperatives data in 1930 are selected from archival files from The Second Historical Archive in China and an adaption of Sun (2009). Urban added value data of the secondary and tertiary industries in 1952 are derived from Fifty Years of Jiangsu Province (EB, 1999). Rural industrial labor force data in 1952 is also from Fifty Years of Rural Economy of Jiangsu Province (EB, 2000).

(2) Land use data includes modern land use spatial pattern, historical distribution of arable land and water bodies. It is expected to define spatial boundaries of construction land.

The spatial data of historical arable land data is based on Yang et al. (2015). Data of historical water bodies is drawn from Historical Geographic Information System (http://www.fas.harvard.edu/ chgis/), National Provincial Map of Republic of China in 1933, and Atlas of Jiangsu (EG, 1978). Modern (1985) land use data is from the Earth Resources Observation and Science Center (EROS) (http://glovis.usgs.gov/). The urban land use efficiency data (i.e., vacancy ratio) in Qing Dynasty is extracted from Atlas of Ancient China (Qing Dynasty) (Cao et al., 1997) and the survey map of Jiangsu Province in the 1930s.

(3) Basic geographical data includes administrative divisions and topography, which were used for the determination of spatial distribution of construction land.

Historical administrative boundaries and scopes are drawn from Historical Geographic Information System. The elevation and slope data are from the International Scientific Data Mirror Site (http://datamirror.csdb.cn). Road data is from National Provincial Map of Republic of China in 1933 (http://www.xici.net/d217844161.htm) and Transportation History of Jiangsu Province (TCCC, 1995).

\section{Research methods and spatial pattern reconstruction}

The reconstruction of spatial pattern for historical construction land in four typical historical intersects $(1820,1911,1936$, and 1952) includes two procedures, i.e., quantitative estimation and spatial reconstruction. Quantitative estimation provides basis of quantitative control, along with boundary and suitability control, the spatial pattern of historical construction land in Jiangsu can be reconstructed.

\subsection{Quantitative estimation of construction land in typical time intersects}

\subsubsection{Quantitative estimation of urban construction land}

Cities and towns are highly concentrated with population, resources, environment, and socio-economic elements. Urban construction land expands along with the development of any of these elements. Such expansion has the characteristics of temporal sequentiality, periodicity, irreversibility, and spatial particularity. Between 1820 and 1911, the urbanization level (i.e., the proportion of urban population) was maintained at around $10 \%$ ( $\mathrm{Li}$ and $\mathrm{Xu}$, 2008). Most cities were political centers established by the governments and had specially constructed boundary walls. Therefore, it is quite anticipated that the urban population density might fluctuate gradually within city walls and so does the value of per capita urban construction land, the estimation of urban construction land by using data such as city walls 
and four gates along walls can escape meddles with population changes.

In this study, urban construction land in 1820 is estimated mainly based on the perimeter and shape of city/town walls. Data of four gates along the walls and the land vacancy ratio representing arable land and open space that was present within the walls are also used in case for calibration. Moreover, the estimation of the urban construction land at the $\mathrm{Fu}$ (city) level also takes the special form of urban administrative divisions (for example, "Fu" and "County" in the same city, or multiple counties within the same city) (Jin et al., 2016) into consideration. Such estimation has been conducted as in Equation 1:

$$
\left\{\begin{array}{l}
A_{i}=\sum_{j=1}^{s} A U_{j i} \\
A U_{j i}=L_{j i} \times W_{j i} \times\left(1-\alpha_{j i}\right) \\
L_{j i}=W_{j i}=\frac{P_{j i}}{4}
\end{array}\right.
$$

where

$A_{i}$ is the area of urban construction land in $\mathrm{Fu} i$;

$s$ is the number of cities/towns in Fu $i$;

$A U_{j i}$ is the area of construction land in city/town $j$ of $\mathrm{Fu} i$;

$L_{j i}$ and $W_{j i}$ are the length and width of the border of city/town $j$ in $\mathrm{Fu} i$, respectively;

$\alpha_{j i}$ is the vacancy ratio in the border of wall in city/town $j$ of $\mathrm{Fu} i$; and

$P_{j i}$ is the perimeter of the walls of city/town $j$ in $\mathrm{Fu} i$.

The unified form of a city/town is set as rectangular.

(1) In the year 1820

Referred to cities/towns in the south of the Yangtze River that have rich data about four gates (Fan, 1990), the length $\times$ width $\left(L_{i} \times W_{i}\right)$ of a large town is defined at $3.75 \times 10^{6} \mathrm{~m}^{2}$, a medium town at $2.5 \times 10^{6} \mathrm{~m}^{2}$, and a small town at $2.5 \times 10^{5} \mathrm{~m}^{2} . \alpha$ for a provincial capital is set at $65 \%$ (Cao et al., 1997), that for a normal $\mathrm{Fu}$ is $50 \%$, and that for a county/town is $40 \%$. In cases where overlay occurs, Fu takes the priority in area allocation, i.e., the area will be assigned to Fu but not county; and only one county will have the allocation if more counties than one are located within the same city.

The development of society, economy and politics leads to changes in the size and structure of population, and in sequence effects on the demand for land resources, i.e., for residence, production, and business activities. In the early modern period, it is more obvious for the city/town walls to act as the restriction to urban development. Urban construction land progressively broke through the walls and expanded greatly. In this study, the construction land in recent and early modern periods (i.e., in 1911, 1936 and 1952) has been estimated and calculated based on the population size and structure as in equations 2-5.

$$
\begin{gathered}
\left\{\begin{array}{l}
A_{i(t)}=\sum_{j=c, z} A P_{j i(t)} \times P_{T i(t)} \times \beta_{j i(t)}(t=1,2,3) \\
A P_{u i(t)}=A P_{c i(t)}=A P_{z i(t)}
\end{array}\right. \\
A P_{u i(t)}=\left\{\begin{array}{l}
A P_{u i(t-1)}+\left(A P_{\overline{u s}(t)}-A P_{u i(t-1)}\right) \times N_{i(t)}, t=1,2,3 \\
\frac{A_{i(t)}}{N_{\overline{u p i}(t)}}, \mathrm{t}=0
\end{array}\right.
\end{gathered}
$$




$$
\begin{gathered}
A P_{\overline{u s}(t)}=\frac{1}{n} \sum_{m=1}^{n} \frac{L_{m} \times W_{m}}{H_{m(t)} \times P_{H m(t)}} \\
N_{i(t)}=\frac{N_{\overline{u c i}(t)}}{N_{\overline{u p i}(t)}} /\left(\frac{1}{k} \sum_{m=1}^{k} \frac{N_{\overline{u c} m(t)}}{N_{\overline{u p} m(t)}}\right)
\end{gathered}
$$

where

$A_{i(t)}$ is the area of urban construction land of $\mathrm{Fu} i$ in the period of $t$;

$A P_{u i(t)}, A P_{c i(t)}$, and $A P_{z i(t)}$ represent per capita land use of urban, city and town of $\mathrm{Fu} i$ in the period of $t$, respectively;

$P_{T i(t)}$ is the total population size of Fu $i$ in the period of $t$;

$\beta_{j i(t)}$ is the population structure of $\mathrm{Fu} i$ in the period of $t$;

$A P_{u i(t-1)}$ is the per capita urban construction land of $\mathrm{Fu} i$ in the period of $t-1$;

$A P_{\overline{u s}(t)}$ is the average value of per capita urban construction land in the period $t$;

$N_{i(t)}$ is the urban socio-economic modification indicators of $\mathrm{Fu} i$ in the period of $t$;

$t=0,1,2$ and 3 represent the year 1820,1911, 1936 and 1952, respectively;

$H_{m(t)}$ is the number of households within city/town $m$ in the period of $t$;

$P_{H m(t)}$ is the average household population of city/town $m$ in the period of $t$;

$n$ is the number of cities and towns in Jiangsu in the period of $t$;

$N_{\overline{u c i}(t)}$ is the urban socio-economic indicators of $\mathrm{Fu} i$ in the period of $t$;

$N_{\overline{u p}(t)}$ is the urban population of Fu $i$ in the period of $t$;

$\frac{1}{k} \sum_{m=1}^{k} \frac{N_{\overline{u c m}(t)}}{N_{\overline{u p m}(t)}}$ is the average value of per capita urban socio-economic indicators in the period of $t$; and

$k$ is the number of $\mathrm{Fu}$ in Jiangsu in the period of $t$.

(2) In the year 1911

Population in most counties grows and diffuses into surrounding areas. Per capita urban construction land is estimated based on the land area within the walls and population within cities/towns. Per capita urban construction land in each city/town is then amended with the number of business associations and chamber of commerce in the city.

(3) In the years 1936 and 1952

In the middle period of the Republic of China, factories gathered in cities and towns and the national capital began to emerge. During the Anti-Japanese War (1937-1945), all cities in Jiangsu were invaded more or less. Transportation system collapsed, industrial factories were occupied and the handicraft industry had almost been halted. Urban development in this period was in a stagnant status. From the end of the WWII to 1949, the urban population had increased and the urban development had recovered.

Assuming that the urban development level in 1936 was equivalent to that in 1952, per capita urban construction land can be determined based on data in 1952. Per capita urban gross value of products in 1936 can be used to fine calibrate such base data to reflect variations in economies and urban development across regions in 1936. Similarly, per capita added value of the secondary and tertiary industries in 1952 can be utilized as socio- 
economic indicators as well to refine the base data to evidence the imbalance across regions in 1952.

\subsubsection{Quantitative estimation of rural settlement land}

The village is an important component of the settlement system. Rural settlements were initially connected by affinities or clans and formed slowly and stably. The amount and distribution of rural settlement land is affected by the population, family structure, life style, as well as terrain, water resources, and cultivation radius. In general, they were not separated by defined spatial physical barriers (such as city/town walls). The form of social function is generally simple in rural areas. The relationship between the population and arable land affected the evolution of rural settlements. Compared with the urban land, the rural settlement land is expected to be positively correlated with the rural population.

In this study, the rural settlement land area in each period is estimated based on the population size, per capita land area and residential forms as in equations 6-11.

$$
\begin{gathered}
A R_{i(t)}=A P_{r i(t)} \times P_{T R i(t)} \\
A P_{r i(t)}=A P_{b i\left(t_{0}\right)} / \lambda_{i(t)} \\
A P_{b i\left(t_{0}\right)}=A P_{h i\left(t_{0}\right)} / R C_{i\left(t_{1}\right)} \\
A P_{h i\left(t_{0}\right)}=A H_{h i\left(t_{0}\right)} / P_{F i\left(t_{0}\right)} \\
\lambda_{i(t)}=\left\{\begin{array}{l}
1, t=0 \\
\lambda_{h(t)}-\left(\lambda_{h(t)}-\lambda_{l(t)}\right) \times N R_{i(t)}, t=1,2,3 \\
N R_{i(t)}=\frac{N_{\overline{r i}(t)}}{N_{\overline{r p i}(t)}} /\left(\max _{m=1,2, \cdots, k}\left\{\frac{N_{\overline{r c m}(t)}}{N_{\overline{r p m}(t)}}\right\}\right)
\end{array}\right.
\end{gathered}
$$

where

$A R_{i(t)}$ is the area of rural settlement land of $\mathrm{Fu} i$ in the period of $t$;

$P_{T R i(t)}$ is the rural population size of $\mathrm{Fu} i$ in the period of $t$;

$A P_{r i(t)}$ is the per capita rural settlement land of $\mathrm{Fu} i$ in the period of $t$;

$A P_{b i\left(t_{0}\right)}$ and $A P_{h i\left(t_{0}\right)}$ are the per capita land of rural house base area and house size of Fu $i$ in the period of $t_{0}$, respectively;

$\lambda_{i(t)}$ is the ratio of house base land in the rural settlement land of $\mathrm{Fu} i$ in the period of $t$;

$\lambda_{h(t)}$ and $\lambda_{l(t)}$ are the highest and lowest value of $\lambda_{i(t)}$;

$t_{0}$ and $t_{1}$ represent the reference years, i.e., 1933 and 1978;

$t=0,1,2$ and 3 represent 1820,1911, 1936 and 1952, respectively;

$R C_{i\left(t_{1}\right)}$ is the rural house capacity ratio of $\mathrm{Fu} i$ in the period of $t_{1}$;

$A H_{h i\left(t_{0}\right)}$ and $P_{F i\left(t_{0}\right)}$ are the rural average house size per household and average household population of $\mathrm{Fu} i$ in the period of $t_{0}$;

$N R_{i(t)}$ is the rural socio-economic modification indicators of $\mathrm{Fu} i$ in the period of $t$;

$N_{\overline{r c i}(t)}$ is the rural socio-economic indicator of $\mathrm{Fu} i$ in the period of $t$;

$N_{\overline{r p i}_{(t)}}$ is the rural population size of $\mathrm{Fu} i$ in the period of $t$; 
$\max _{m=1,2, \cdots, k}\left\{\frac{N_{\overline{r c m}(t)}}{N_{\overline{r p m}(t)}}\right\}$ is the maximum value of per capita rural socio-economic indicators in

the period of $t$; and

$k$ is the number of $\mathrm{Fu}$ in Jiangsu in the period of $t$.

Before the 1980s, the rural socio-economic development was slow, the land use structure was relatively stable, and the housing structure was mostly single-floor. After the Reform and Opening in China, with the improvement of the agricultural economy, the living conditions have been continuously improved (Zheng, 2011; Wu et al., 2008).

(1) In the year 1820

The rural house capacity ratio in 1820 is assumed to be as the same as that in 1978 with a value of 0.245 (Lin et al., 2015). It is then finely adjusted in different agricultural regions by taking into consideration the effects of the number and species of livestock and poultry. Sorted by the total number of livestock and poultry from the maximum to the minimum, the whole province can be grouped into three regions: the rice-tea area (including Jiangning, Zhenjiang, Changzhou, Suzhou and Taicang), Yangtze rice-wheat area (including Tongzhou, Haimen, Yangzhou, Huai'an and Sizhou), and wheat-kaoliang area (including Hai and Xuzhou). The corresponding adjusted rural house capacity ratio value for these three regions is $0.27,0.245$ and 0.22 respectively.

Based on the survey data of 1933 (Bo, 1941), per capita rural house size is set at $16.81 \mathrm{~m}^{2}$, $20.44 \mathrm{~m}^{2}$ and $14.08 \mathrm{~m}^{2}$ in sequence. Therefore, per capita rural house base area can then be calculated as $62.26 \mathrm{~m}^{2}, 83.43 \mathrm{~m}^{2}$ and $64 \mathrm{~m}^{2}$ respectively for three regions. Combined with the rural population in an individual $\mathrm{Fu}$, the amount of rural settlement land in each $\mathrm{Fu}$ can be obtained.

(2) In the year 1911

Per capita house base area remains stable for all three time intersects in this study.

Moreover, it is expected that more and more rural land would be used for transportation, infrastructure, and provision of public facilities along with the rural development. Thus the proportion of public construction land also needs to be taken into consideration. During 1820 and 1911, the government enacted several policies to encourage agricultural production to meet needs due to the war, famine, and population increase. Rural agricultural companies were progressively emerged and the rural area experienced a series of farmland and water conservancy facility construction. In this case, per capita rural agricultural company is also going to be used as an adjusting parameter for the proportion of public construction land at $\mathrm{Fu}$ level.

(3) In the year 1936

The rural cooperative movement rapidly developed under the guidance and promotion from the central government of the Republic of China. By 1936, the average rural cooperatives at county level in south and north of the Yangtze River had reached 71 and 56 respectively (Sun, 2009). Setting the village as the organization unit, mutual aid groups subordinating to rural cooperatives were established. It is expected that farmers would be entitled to join mutual aid groups as members. Along with the bao-jia system (an old administrative system organized on the basis of households, each bao consisting of 10 jias, and each jia consisting of 10 households), mutual aid groups vigorously developed local economic output, 
water conservancy, industries, and comprehensive improvement such as birth control, education, hygiene, and religion (Zhu and Wang, 2008). During 1911 and 1936, there was some increase in the proportion of rural public construction land. Therefore, per capita rural cooperatives are used as the basis for the differential treatment of the proportion of public land.

(4) In the year 1952

People's Republic of China started a comprehensive land reform in 1950. A number of measures were put into action to boost agricultural production, construct water conservancy infrastructure and improve soil quality. In 1951, preliminary agriculture cooperatives began to be established. In 1952, the output of main agricultural products reached the maximum in history. At the time, among the whole agricultural labor force, besides farming, forestry, animal husbandry and fishery, most concentrated in the agro-industry such as exploiting natural resources (i.e., mining, salt extraction, forest cutting, etc.), processing agricultural byproducts, and repairing industrial products. Therefore, the percentage of the agro-industrial labor force in the rural labor force has been chosen to differentiating the percentage of public land in each individual $\mathrm{Fu}$.

Combined with data in 1985 interpreted from remote sensing images, the estimation of construction land in Jiangsu for all time intersects is shown in Table 1 and Figure 3.

Table 1 Reconstructed historical construction land $\left(\mathrm{km}^{2}\right)$ at each Fu (city) in Jiangsu Province

\begin{tabular}{|c|c|c|c|c|c|c|}
\hline \multirow{2}{*}{$\mathrm{Fu}$} & \multicolumn{3}{|c|}{ Year } & \multirow{2}{*}{ City } & \multicolumn{2}{|c|}{ Year } \\
\hline & 1820 & 1911 & 1936 & & 1952 & 1985 \\
\hline Jiangning $\mathrm{Fu}$ & 61.97 & 66.22 & 105.27 & Nanjing & 107.28 & 792.68 \\
\hline Zhenjiang Fu & 78.26 & 60.47 & 74.58 & Wuxi & 107.17 & 394.34 \\
\hline Changzhou Fu & 149.53 & 76.06 & 157.05 & Xuzhou & 225.63 & 1832.12 \\
\hline Suzhou Fu & 197.32 & 87.03 & 111.81 & Changzhou & 76.01 & 336.83 \\
\hline Taicang Zhou & 19.36 & 12.72 & 27.40 & Suzhou & 145.35 & 532.60 \\
\hline Tong Zhou & 54.56 & 145.11 & 219.91 & Nantong & 301.81 & 331.75 \\
\hline Haimen Ting & 11.41 & 17.52 & 37.58 & Lianyungang & 103.66 & 996.26 \\
\hline Yangzhou Fu & 169.79 & 192.11 & 315.29 & Huaiyin & 135.44 & 1564.72 \\
\hline Huai'an Fu & 85.02 & 164.55 & 254.04 & Yancheng & 227.85 & 987.07 \\
\hline Sizhou & 36.73 & 19.21 & 49.03 & Yangzhou & 163.31 & 595.68 \\
\hline Haizhou & 30.07 & 80.90 & 116.67 & Zhenjiang & 61.27 & 306.11 \\
\hline \multirow[t]{2}{*}{ Xuzhou Fu } & 69.45 & 121.55 & 203.76 & Taizhou & 193.35 & 454.94 \\
\hline & & & & Suqian & 132.19 & 1562.12 \\
\hline Total & 963.46 & 1043.46 & 1672.40 & Total & 1980.34 & 10687.20 \\
\hline
\end{tabular}

\subsection{Spatial reconstruction of construction land}

\subsubsection{Spatial allocation principles}

In this study, the spatial reconstruction of construction land conforms to a few principles:

(1) Natural resources such as the climate and geomorphology related to the distribution of construction land do not change along with the time line;

(2) Modern construction land is the outcome of the gradual expansion of historical construction land. The historical construction land should not locate beyond the boundary of corresponding modern urban construction land and rural settlement land; 
(a) 1820
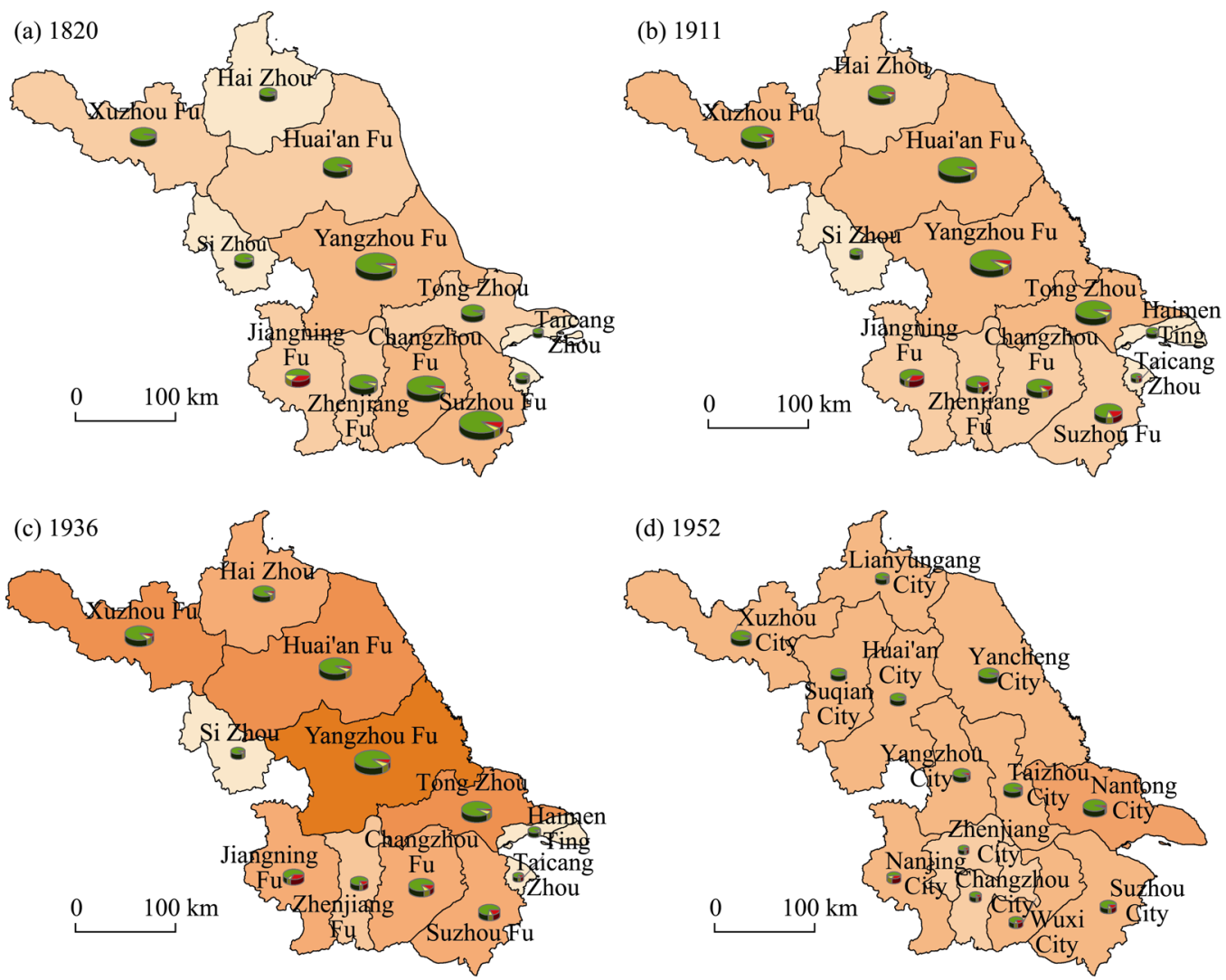

(d) 1952

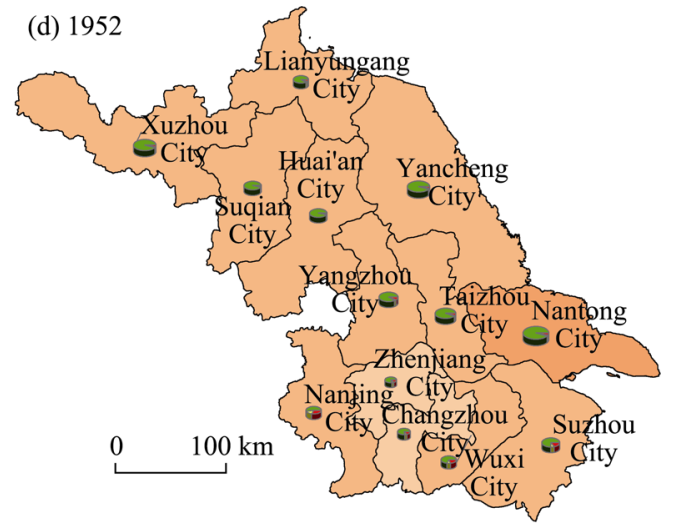

(e) 1985

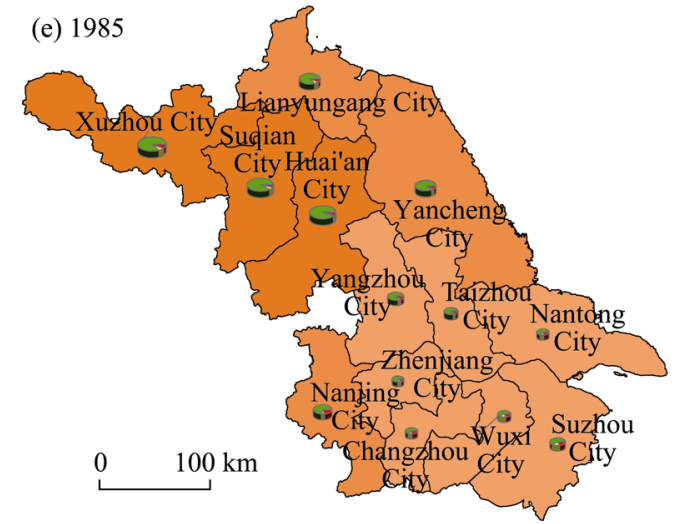

Figure 3 Changes of historical construction land in each Fu (City) in Jiangsu Province

(3) Historical urban administrative divisions are distributed within the scope of modern cities and towns. Extinct cities and towns that once existed during our study period are supplemented based on the literature reviews;

(4) Only one-way evolution is taken into consideration, i.e., urban construction land evolves from town land or settlement land in the earlier period but not vice versa.

\subsubsection{Reconstruction methods}

The spatial distribution of construction land is affected by both natural and human factors. Indicators of the natural conditions include the elevation, slope, and distance to water areas. 
Socio-economic indicators mainly include the distance to roads, the distance to cities/towns, and the distance to rural settlements. Meanwhile, the base map of land suitability has been configured by weights which are determined by applying the entropy weight method. Figure 4 shows the detailed technical process.

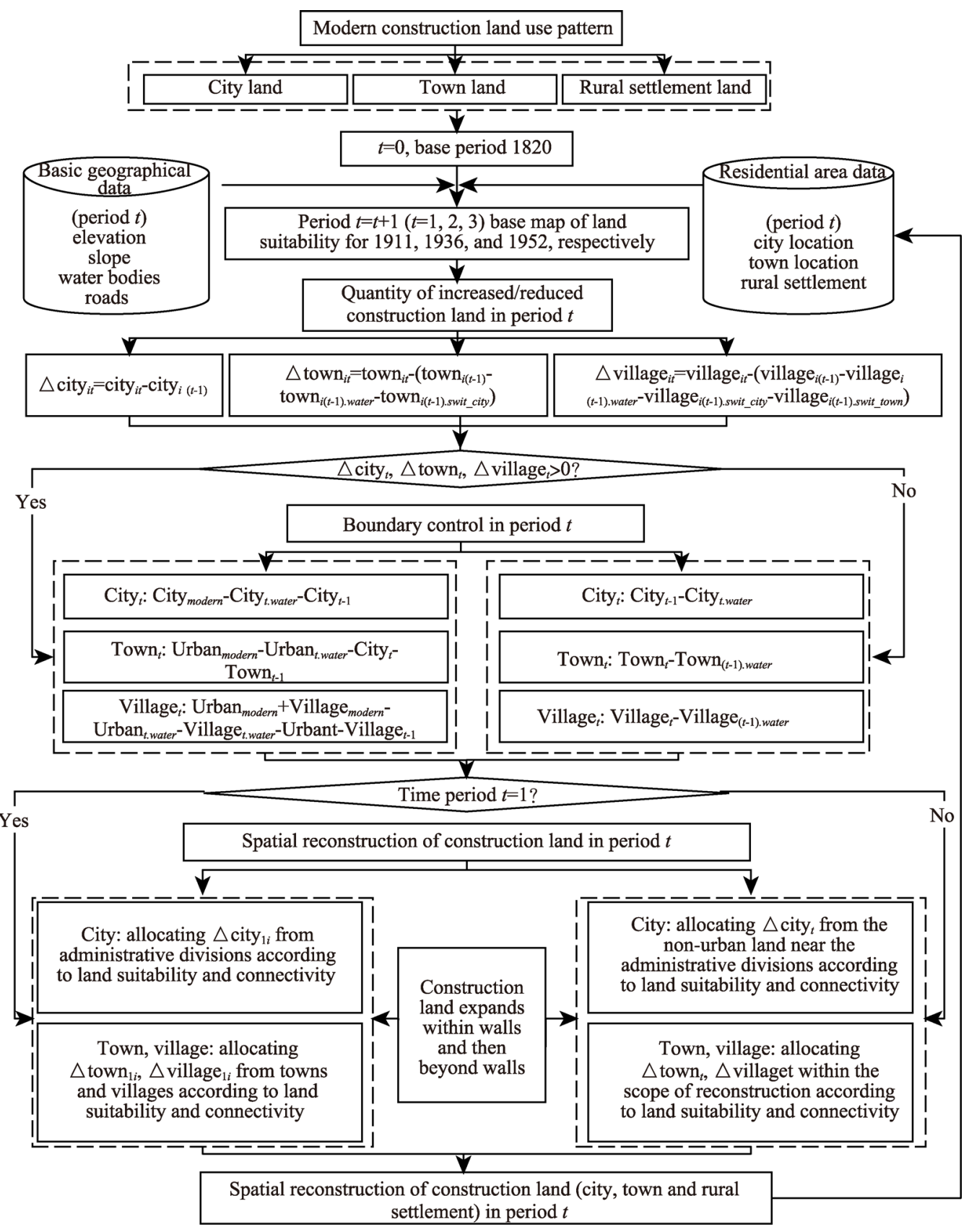

Figure 4 Spatial reconstruction of historical construction land

\subsubsection{Reconstruction results}

For the year 1820, the urban construction land and rural settlement land are defined by the 
number of grids corresponding to the estimated quantity while shapes of city/town walls are used as control borders. The suitability and connectivity of grids are also been considered (Lin et al., 2015).

As for the years 1911, 1936 and 1952, the urban construction land and rural settlement land are assumed to expand only within the scope of corresponding city/town/village at contemporary time. The city land expanded within walls and then beyond the walls according to the suitability and connectivity characteristics. The result of the land suitability evaluation has been deemed as a controlling parameter.

In order to improve the visual effect, the Boolean data in $200 \mathrm{~m} \times 200 \mathrm{~m}$ grids has been converted into proportional data in $1 \mathrm{~km} \times 1 \mathrm{~km}$ grids in Figure 5. As shown in Figure 5, the total construction land in Jiangsu has generally increased over the study period. However, there are significant differences across regions and periods. The spatial distribution of construction land exhibits its proclivity to water bodies and road networks and the great polarization effect of existent residence. Specifically, the construction land in 1820, 1911, 1936 and 1952 is shown below.

(a) 1820

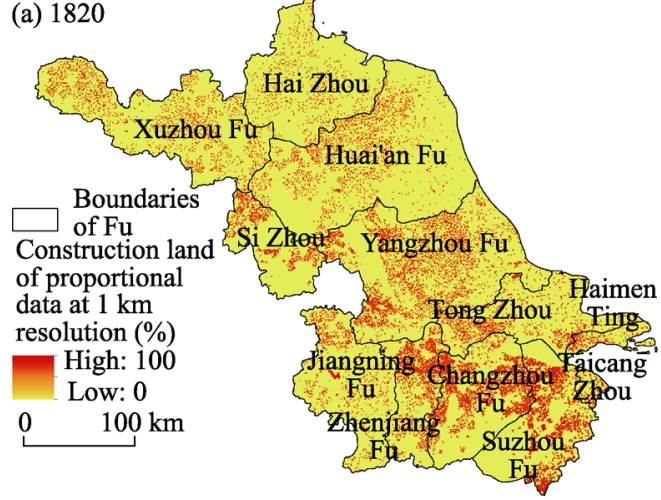

(c) 1936

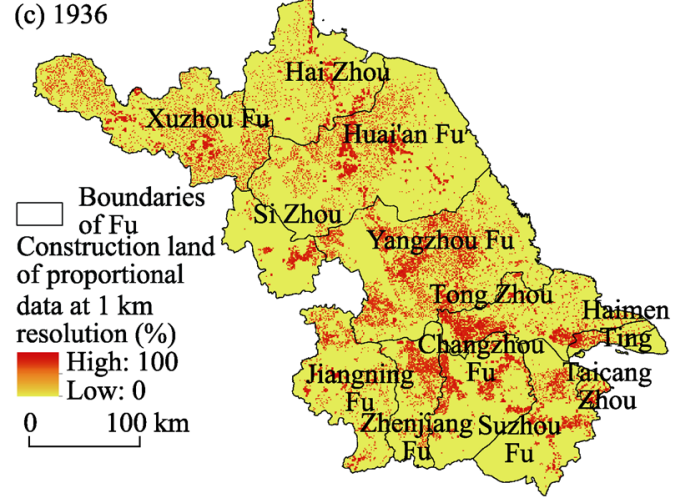

(b) 1911

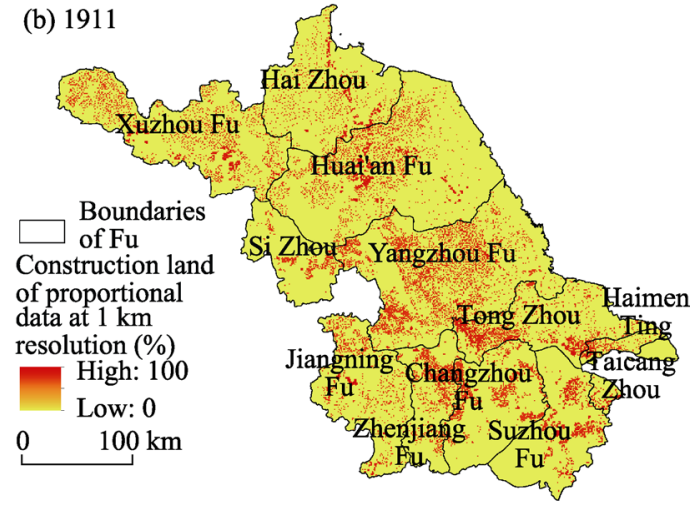

(d) 1952

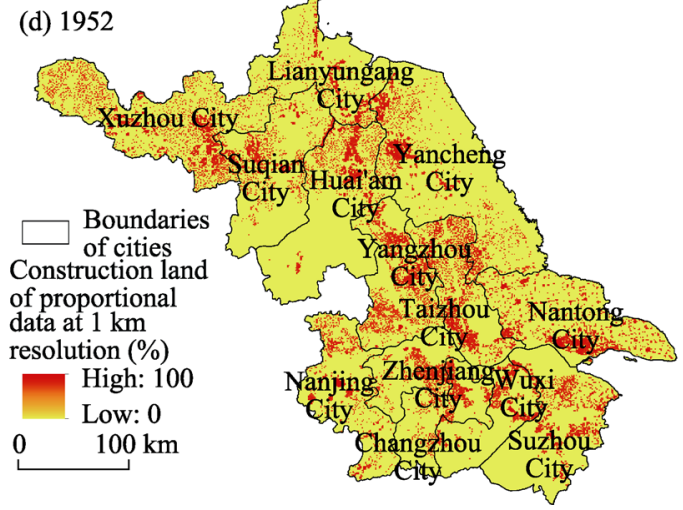

Figure 5 Spatial pattern of historical construction land in Jiangsu Province

(1) In the year 1820

The construction land was distributed mainly in southern Jiangsu, about $53 \%$ of it is in Jiangning, Zhenjiang, Changzhou, Suzhou and Taicang.

It is straightforward that water bodies were of a great effect on the spatial pattern of the construction land. Rural settlements in central Jiangsu were mainly located at the junction of 
the main tributaries and along rivers/lakes to meet human production and living needs.

The densest distribution of rural settlements occurred in Zhenjiang, Changzhou, and the central and northern Suzhou from the south of the Yangtze River to Taihu Lake. The second densest area was found in western and southwestern Yangzhou along the Gaoyou Lake, western Tongzhou along the north of the Yangtze River, northwestern Huai'an along the downstream area of the Yellow River in northern Jiangsu Province.

(2) In the year 1911

The density of construction land in southern Jiangsu decreased rapidly because of the civil war. The total construction land slightly increased in central Jiangsu, and Huai'an, Xuzhou and Haizhou in northern Jiangsu. The construction land distribution density slightly increased in central Huai'an in northern Jiangsu and southwestern Xuzhou.

(3) In the year 1936

The construction land was densely distributed in western Tongzhou, central Yangzhou in central Jiangsu, and southeastern Xuzhou along the Luoma Lake, southern Haizhou along the Guanhe River, central and northern Huai'an, and southwestern Sizhou in northern Jiangsu. At the time, the total construction land rapidly increased with the construction of roads and railroads.

(4) In the year 1952

The construction land continued to increase. In particular, the construction land density rapidly increased in the coastal areas of Nantong.

In contrast, the construction land in central and southern Huai'an slightly decreased probably because of the reduction of water bodies.

\section{Verification of results}

\subsection{Verification of trends and correlation}

(1) Urban land

In the mid-Qing Dynasty (i.e., 1820), the percentage of urban population is higher in Jiangning and Suzhou than that in other cities since they are where the Jiangning Administrative Commissioner's Office and Jiangsu Provincial Administrative Commissioner's Office locate respectively. The construction land in these two cities takes approximately an half of the total urban land in Jiangsu Province.

Urban development in central and northern Jiangsu is slow. By the end of the Qing Dynasty and early years of the Republic of China (i.e., 1911), urban population in southern Jiangsu had dropped dramatically but slightly increased in central and northern Jiangsu due to the imbalanced occurrences of the war aftermath.

Till 1936, national industry and commerce had been reestablished and developed in cities and towns while urban land had been consistently increased. Urban land takes approximately $16 \%$ of the total construction land in Jiangsu in 1936. Urban land in southern Jiangsu is still of the greater percentage than that in central and northern Jiangsu.

In 1952, the national economy was almost completely recovered from years of wars while urban construction and development rapidly increased.

The above detailed outline of urban land changes in our study period anchoring on our 
selected several time intersects shows that our reconstructed urban land is consistent with historical events and our reconstruction data is compatible with the overall trend.

(2) Rural settlement land

Arable land is essential for rural households while the agricultural cultivation economy is the base for the existence and development of rural settlements. Development of arable land and that of rural settlements are interrelated and mutually promoted. Therefore, the quality of our quantitative estimates can be accessed by a correlation analysis between the amount of arable land and that of the rural settlement land.

The arable land data for the Qing Dynasty is compiled based on Cao et al. (2014), for the Republic is generated from China's Agricultural Production and Commerce Statistics $(\mathrm{Xu}$, 1983), Statistical Analysis of Chinese Land Use (GSB, 1936), Agriculture Development in China: 1368-1968 (Dwight, 1984), and for after the founding of the People's Republic is taken from National Land Survey and Chinese Economic Statistics.

The correlation coefficient between the amount of rural settlements and that of arable land at $\mathrm{Fu}$ (city) level has been estimated at 0.531 for the year 1820 with $p<0.1,0.720$ for the year 1911 with $p<0.01,0.746$ for the year 1936 with $p<0.01$, and 0.769 for the year 1952 with $p<0.01$. Figure 6 illustrates the correlation analysis results.
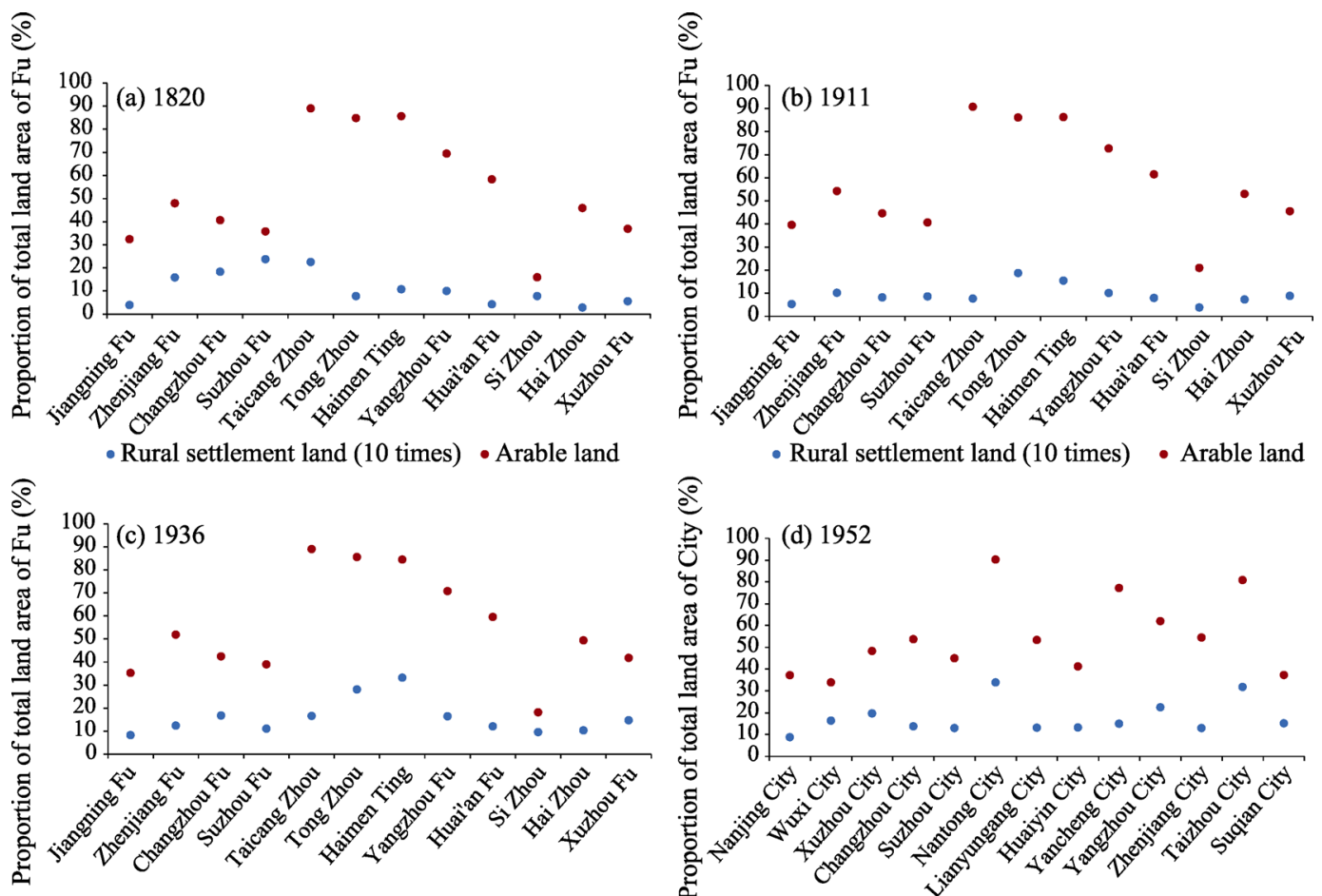

- Rural settlement land (10 times) - Arable land

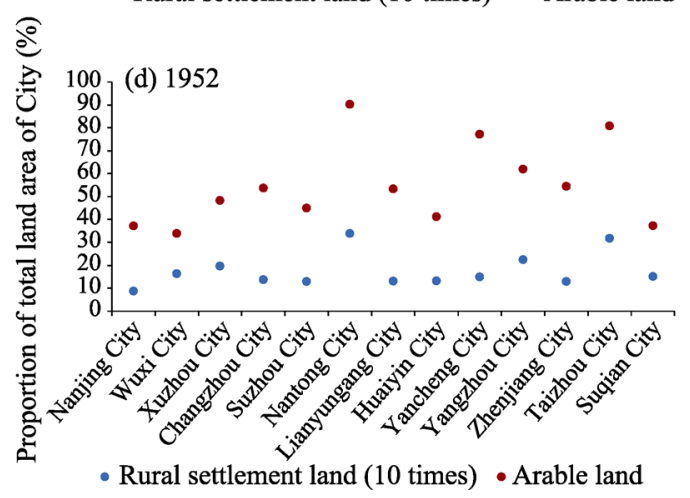

Figure 6 Correlation between the amount of arable land and that of rural settlement land at Fu (city) level

\subsection{Quantitative verification}

To verify the effectiveness of our methodology, our reconstructed dataset is compared to corresponding historical maps in which historical data for Jiangsu Province is accessible. The quantitative verification is conducted with indicators such as the absolute error, relative 
error, and coverage ratio between the number of towns/villages identified in the reconstruction results to that present in historical maps. The calculations of these indicators are conducted by applying equations 12-14:

$$
\begin{gathered}
A E=(r r-h m) \\
R E=(r r-h m) / h m \times 100 \% \\
C R=c a / h m \times 100 \%
\end{gathered}
$$

where $A E$ and $R E$ are respectively absolute error, relative error between the number of reconstruction towns/villages and the number from historical maps;

$C R$ is the coverage ratio of towns/villages in historical maps in a range of $1 \mathrm{~km}$ of the rebuilding towns/villages;

$r r$ is the number of towns/villages identified in the rebuilding process;

$\mathrm{hm}$ is the number of towns/villages in historical maps; and

$c a$ is the number of towns/villages in historical maps in a $1 \mathrm{~km}$ buffer of the towns/ villages identified in the rebuilding process.

Such verification process has been conducted upon four selected counties/cities:

Danyang County representing hilly land in Nanjing-Zhenjiang-Yangzhou region (Region I);

Changshu County representing watershed plain land around Taihu Lake (Region II);

Nantong City representing alluvial plain of the Yangtze River (Region III); and

Suqian County representing the Yellow River Flood Plain (Region IV).

Military surveying map in the 1930s (http://blog.sina.com.cn/kcj) has been used as reference in this verification. $1 \mathrm{~km}$ has been set as the buffer zone for error detection, i.e., the deviation within the distance of $1 \mathrm{~km}$ is deemed to be compatible or ignorable. Table 2 and Figure 7 show the verification results.

Table 2 Accuracy of the reconstruction results in sample areas in 1936

\begin{tabular}{llllll}
\hline Sample & \multicolumn{1}{c}{ Location } & \multicolumn{1}{c}{ Region represented } & $A E$ & $R E$ & $C R$ \\
\hline Danyang & Southern Jiangsu & $\begin{array}{l}\text { Region I: hilly land areas in Nanjing-Zhenjiang- } \\
\text { Yangzhou }\end{array}$ & -139 & $-30.82 \%$ & $76.72 \%$ \\
Changshu & Southern Jiangsu & $\begin{array}{l}\text { Region II: watershed plain land areas of Taihu } \\
\text { Lake }\end{array}$ & -40 & $-4.45 \%$ & $62.03 \%$ \\
Nantong & Central Jiangsu & Region III: alluvial plain of the Yangtze River & -31 & $-4.45 \%$ & $56.67 \%$ \\
Suqian & Northern Jiangsu & Region IV: the Yellow River Flood Plain & 176 & $32.47 \%$ & $74.72 \%$ \\
\hline & Average & & -34 & $-1.31 \%$ & $65.80 \%$ \\
\hline
\end{tabular}

In our four selected sample areas, there are a total of 2554 reconstructed towns/villages and 2588 corresponding towns/villages in the historical maps. The total relative error is $-1.31 \%$. In particular, the relative error in Region II and Region III is at $-4.45 \%$. The relative error in Region I and Region IV is $-30.82 \%$ and $32.47 \%$ respectively.

As to the accuracy test, valid reconstructed towns/villages within $1 \mathrm{~km}$ buffer zone of their counterparts in the historical map reached $65.8 \%$ of the total. Specifically, such accuracy reached $76.72 \%$ in Region I, $74.72 \%$ in Region IV, $62.03 \%$ in Region II and $56.67 \%$ in Region III. 
Danyang (I): results of reconstruction

(a1)

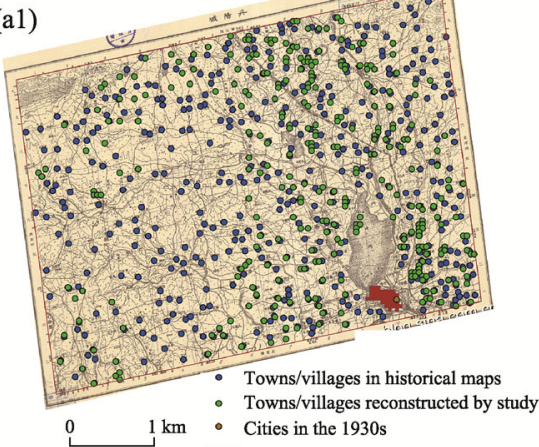

Changshu (II): results of reconstruction

(b1)

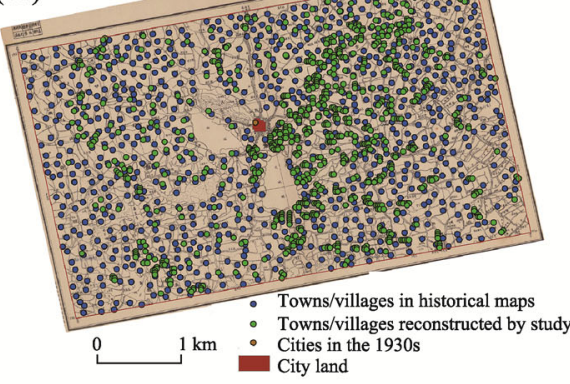

Nantong (III): results of reconstruction

(c1)

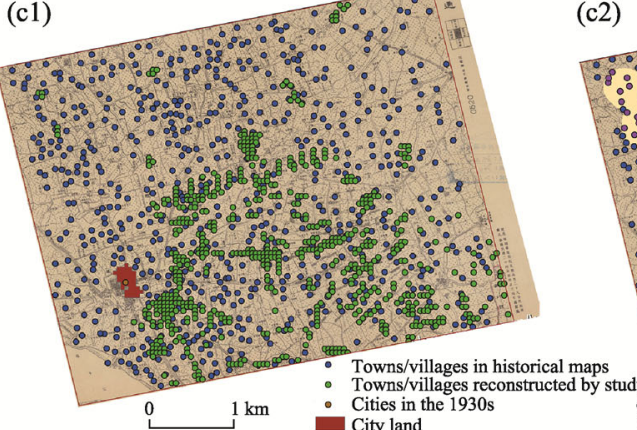

Danyang (I): verification of reconstruction

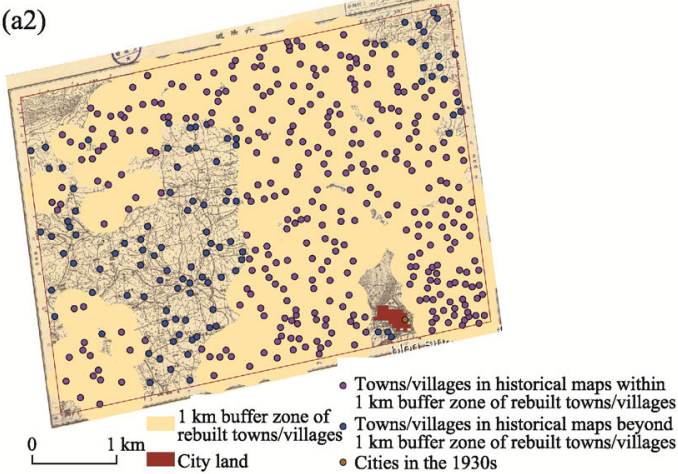

Changshu (II): verification of reconstruction

(b2)

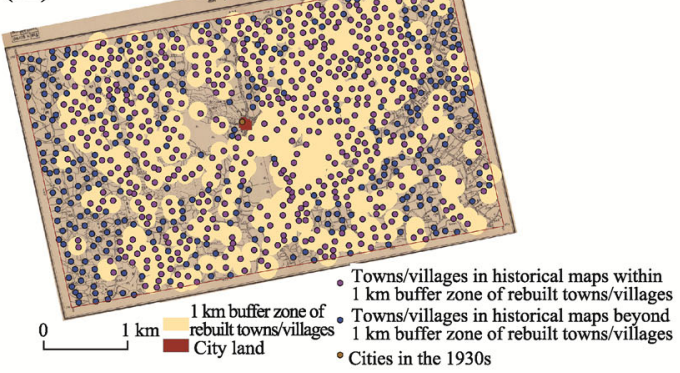

Nantong (III): verification of reconstruction
Suqian (IV): results of reconstruction

(d1)

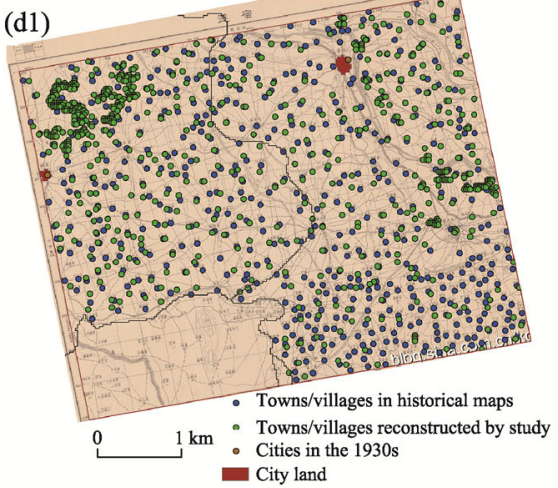

Suqian (IV): verification of reconstruction

(d2)

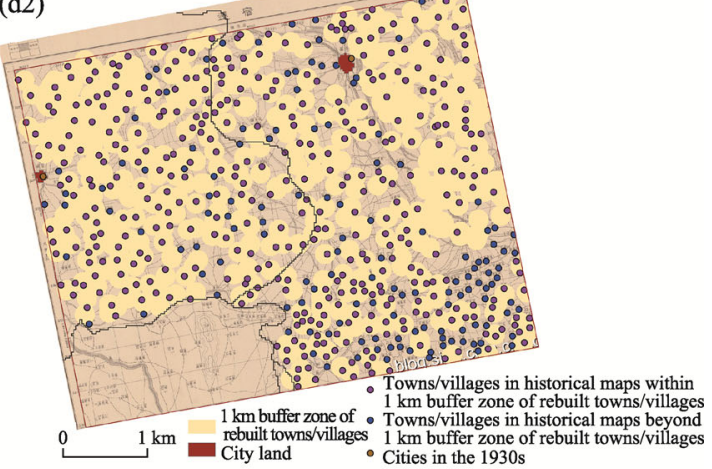

Figure 7 Accuracy of reconstruction results in 1936 referring to historical maps 


\section{Discussion and conclusions}

This paper aims to provide a new perspective on reconstructing the spatial pattern for historical construction land, especially urban construction land and rural settlement land, by focusing on characteristics of historical land use changes while incorporating data from various sources including historical documents, statistics, land use, and basic geographic data.

Urban construction land is proposed to be estimated based on indicators such as city walls and four gates along city walls while in a few cases need fine calibration with population and per capita construction land data. The rural settlement land is calculated by multiplying rural population data and per capita housing allowance.

Thus, the spatial pattern of historical construction land in Jiangsu can be reconstructed in $200 \mathrm{~m} \times 200 \mathrm{~m}$ grids for our four study periods in the last 200 years with quantitative control, border control, and land suitability control and the connectivity among land use types.

Our study outcome indicates that great differences present across regions in 1820. For reference, for Jiangsu Province at the similar time being, He et al. (2002) estimates that the total urban land in Jiangsu Province was $185.77 \mathrm{~km}^{2}$ (in which Jiangning was $60 \mathrm{~km}^{2}$ ) by using the perimeter of walls recorded in Jiaqing Rebuilt Chi Unification; Pan et al. (2015) finds out that the total urban land was $115.54 \mathrm{~km}^{2}$ based on data derived from He et al. (2002) and calibrated with the percentage of urban population; Lin et al. (2015) concludes that the total urban land was $222.9 \mathrm{~km}^{2}$ and Jiangning alone took $146.35 \mathrm{~km}^{2}$.

This study classified urban construction land into city land and town land based on a refined analysis of historical documents. Some survey maps at that time show that a large amount of arable land and open space presented within the walls of cities in historical periods, e.g., the land vacancy ratio in Jinling was $65 \%$. Thus, although city walls can be considered a physical boundary between urban and rural landscapes, it might not be appropriate to treat city walls as a boundary between urban construction land and rural settlement land in terms of the type and extent of land use. Therefore, this study uses the land vacancy ratio to refine the total urban construction land calculated by the perimeters of city walls to come up with the value of total urban construction land in 1820 at $58.18 \mathrm{~km}^{2}$ (of which $21 \mathrm{~km}^{2}$ is in Jiangning). This result is compatible with the dynamic evolution theory about the development of urban construction land. It has been widely observed that in history urban construction land expands with the increase of population by "filling in" the space within city walls then expands further beyond city walls.

The variation in the estimated amount of rural settlement land across studies is mainly resulted from the choice of one substitute indicator, i.e., per capita rural land use.

Pan et al. (2015) estimates that the total rural settlement land in 1820 was $4724.68 \mathrm{~km}^{2}$ based on per capita rural land use level in 1985. Lin et al. (2015) shows that the total rural settlement land was $783.93 \mathrm{~km}^{2}$ in history by using per capita rural housing allowance value and the house capacity ratio in 1978. This study finds out that the total rural settlement land was $853.23 \mathrm{~km}^{2}$ in 1820 with the house capacity ratio in 1978 and the value of per capita rural housing allowance in the 1930s. These historical values are preferred in this study for the closeness of their time to 1820 .

Generally, academic contributions of this study mainly include three aspects:

(1) Expanding the list of reconstruction objects and the time span of reconstruction 
Most contemporary studies focus on either urban construction land or the composite of urban land and rural settlements. This study further divides urban land into cities and towns, which supplements the previous untouched/neglected construction land at the county level. Moreover, this study replenishes three more historical periods covering recent and early modern times to classic studies with only one historical period by using proxy coefficients, which enables the continuity of reconstructing the spatio-temporal pattern of historical land use.

(2) Including more variables and strengthening the data calibration

Besides classic variables such as historical population and per capita land use, this study integrates more variables such as data about four gates along the city walls and the rural house capacity ratio into consideration based on extensive literature review. Regarding the variation among variables in terms of suitability across regions, coefficients such as the number of per capita urban business associations and chambers of commerce and that of per capita rural cooperative entities are also employed in this study to calibrate the reconstructed historical construction land to further approach its historical true values.

(3) Reinforcing the verification process

To make up the deficiency of contemporary studies in the research outcome verification process, this study combines three direct and indirect methods to strengthen the assessment effectiveness over the rationality of our reconstructed historical land use pattern. These three methods include the consistency analysis of the process of construction land changes with the tendency of corresponding regional land use pattern, the correlation analysis between the distribution of rural settlement land and the arable land, and the quantitative analysis of the spatial distribution for historical construction land at typical time intersects.

Historical events are of the nature non-firsthand, irreversibility and lack of spatial pattern information. Meanwhile, the spatial pattern of construction land is influenced by various factors, especially those social factors, which imply great uncertainty. This study aims to reconstruct the historical construction land based on a few assumptions about natural resources, socio-economic conditions, and land use principles. Therefore, each individual typical time intersect only stands for the average status during that historical period and the outcome of such reconstruction is only a feasible scenario based on rational reasoning. However, our proposed comprehensive reconstruction approach is of the great reference value to reconstructing historical construction land and even multiple (or all) land use types with greater time span and/or greater geographic coverage.

\section{References}

Bai S Y, Zhang S W, Zhang Y Z, 2007. Digital rebuilding of LUCC spatial-temporal distribution of the last 100 years: Taking Dorbod Mongolian Autonomous County in Daqing City as an example. Acta Geographica Sinica, 62(4): 427-436. (in Chinese)

Bao J L, Gao S, 2016. Traditional coastal management practices and land use changes during the 16-20th centuries, Jiangsu Province, China. Ocean \& Coastal Management, 124: 10-21.

Bo K, 1941. China Land Use. Department of Economics: University of Nanking Agricultural College. (in Chinese)

Cao S J, 2002. Urban population of Jiangsu Province in the Qing Dynasty. Journal of Hangzhou Normal University (Social Sciences), (4): 50-56. (in Chinese)

Cao W R, Zhen X H, Huang S Z, 1997. Atlas of Ancient China (Qing Dynasty). Beijing: Cultural Relics Press. (in 


\section{Chinese)}

Cao X, Jin X B, Wang J S et al., 2014. Reconstruction and change analysis of cropland data of China in recent 300 years. Acta Geographica Sinica, 69(7): 896-906. (in Chinese)

Dwight P H, 1984. Agriculture Development in China: 1368-1968. Edinburgh: Edinburgh University Press.

Editorial Group (EG) of Atlas of Jiangsu, 1978. Atlas of Jiangsu. Nanjing: Jiangsu Map Publishing House. (in Chinese)

Editorial Board (EB) of Fifty Years of Jiangsu Province, 1999. Fifty Years of Jiangsu Province. Beijing: China Statistics Press. (in Chinese)

Editorial Board (EB) of Fifty Years of Rural Economy of Jiangsu Province, 2000. Fifty Years of Rural Economy of Jiangsu Province. Beijing: China Statistics Press. (in Chinese)

Fan S Z, 1990. Jiangnan Towns in the Ming and Qing Dynasty. Shanghai: Fudan University Press. (in Chinese)

Fang X Q, Zhang W B, Zhang L S et al., 2002. The urban expansion and the evolution of urban fringe in Beijing in the 20th century. City Planning Review, 26(4): 56-60. (in Chinese)

Fu L X, 2009. A new study on the establishment of Jiangsu Province in the Qing Dynasty. Studies in Qing History, 73(2): 23-31. (in Chinese)

Government Statistic Bureau (GSB), 1936. Statistical Analysis of Chinese Land Use. Nanjing: Zhongzheng Publishing House. (in Chinese)

Gu C L,Hu L Q, Zhang X M et al., 2011. Climate change and urbanization in the Yangtze River Delta. Habitat International, 35: 544-552.

He F N, Ge Q S, Zhang J Y, 2002. Reckoning the areas of urban land use and their comparison in the Qing Dynasty in China. Acta Geographica Sinica, 57(6): 709-716. (in Chinese)

$\mathrm{Hu}$ X H, Yang G Q, Zhang X et al., 2007. The change of land use for rural residency and the driving forces: A case study in Xiantao City, Hubei Province. Resources Science, 29(3): 191-197. (in Chinese)

$\mathrm{Hu}$ Z Z, 1994. Settlement Geography. Taiwan: San Min Book. (in Chinese)

Ji Y, Sun W, Li G et al., 2009. Space-time features analysis of land use/cover change in Guangzhou urban built-up area from 1907 to 1968. Journal of South China Normal University (Natural Science Edition), 123(1): 121-126. (in Chinese)

Jiaqing Rebuilt Chi Unification, 1986. Beijing: Zhonghua Book Company. (in Chinese)

Jiangsu Geography Institute of Geography Department in Nanjing Normal University (JGI), 1982. Urban Historical Geography of Jiangsu. Nanjing: Jiangsu Science and Technology Press. (in Chinese)

Jin Q M, 1988. Rural Settlement Geography. Beijing: Science Press. (in Chinese)

Jin X B, Pan Q, Yang X H et al., 2016. Reconstructing the historical spatial land use pattern for Jiangsu Province in mid-Qing Dynasty. Journal of Geographical Sciences, 26(12): 1689-1706.

Li B B, Xu F, 2008. The research on urbanization rate and staging in modern China. Journal of East China Normal University (Philosophy and Social Sciences), 197(3): 34-41. (in Chinese)

Li S, Luo X Q, 2014. Study on spatiotemporal expansion feature of urban based on multisource data using remote sensing technique in Guiyang city in the latest 700 years. Journal of Natural Resources, 29(10): 1734-1745. (in Chinese)

Lin Y N, Jin X B, Yang X H et al., 2015. Data set establishment and spatial reconstruction of built-up area in the Mid Qing Dynasty: Method and case study. Geographical Research, 34(12): 2329-2342. (in Chinese)

Liu M L, Tian H Q, 2010. China's land cover and land use change from 1700 to 2005: Estimations from high-resolution satellite data and historical archives. Global Biogeochemical Cycles, 24(3): 285-286.

Ma R F, Wang T F, Zhang W et al., 2016. Overview and progress of Chinese geographical human settlement research. Journal of Geographical Sciences, 26(8): 1159-1175.

Pan Q, Jin X B, Zhou Y K, 2015. Gridding reconstruction of land use pattern in Jiangsu Province in the mid-Qing Dynasty. Acta Geographica Sinica, 70(9): 1449-1462. (in Chinese) 
Ray D K, Pijanowskia B C, 2010. A backcast land use change model to generate past land use maps: Application and validation at the Muskegon River watershed of Michigan, USA. Journal of Land Use Science, 5(1): 1-29.

Saunders D, 2012. Arrival City. Shanghai: Shanghai Translation Publishing House.

Schaldach R, Alcamo J, Koch J et al., 2011. An integrated approach to modelling land-use change on continental and global scales. Environmental Modelling \& Software, 26(8): 1041-1051.

Song W, Chen B M, Yang H et al., 2008. Analysis on the status quo of residence base resources in rural areas of China. Chinese Journal of Agricultural Resources and Regional Planning, 29(3): 1-5. (in Chinese)

Sun Z X, 2009. The research on Jiangsu rural cooperatives in the Republican Period (1927-1937) [D]. Nanjing: Nanjing Agricultural University. (in Chinese)

The Second Historical Archives of China (SHAC), 1998a. Archives Compilation of History of Republic of China (Third Series Agriculture and Commerce). Nanjing: Jiangsu Ancient Books Press. (in Chinese)

The Second Historical Archives of China (SHAC), 1998b. Archives Compilation of History of Republic of China (Fifth Series Finance and Economy). Nanjing: Jiangsu Ancient Books Press. (in Chinese)

Tian H Q, Kamaljit B, Tao B et al., 2014. History of land use in India during 1880-2010: Large-scale land transformations reconstructed from satellite data and historical archives. Global \& Planetary Change, 121(10): $78-88$.

Traffic Chronicles Compilation Committee (TCCC), 1995. Transportation History of Jiangsu Province. Beijing: China Communications Press. (in Chinese)

Wang S H, 1984. Regional Studies of China's Modernization: Jiangsu Province. Taipei: Institute of Modern History. (in Chinese)

Wu W H, Niu S W, Guo X D et al., 2008. The empirical analysis of the village pattern evolution in the central part of Huang-Huai-Hai Plain. Geographical Research, 27(5): 1017-1026. (in Chinese)

Xu D, 1983. China's Agricultural Production and Commerce Statistics in Recent History. Shanghai: Shanghai People's Publishing House. (in Chinese)

Xu X Q, Zhou Y X, Ning Y M, 2009. Urban Geography. Beijing: Higher Education Press. (in Chinese)

Yan Z W, Wang J, Xia J J et al., 2016. Review of recent studies of the climatic effects of urbanization in China. Advances in Climate Change Research, 7: 154-168.

Yang X H, Jin X B, Du X D et al., 2016. Multi-agent model-based historical cropland spatial pattern reconstruction for 1661-1952, Shandong Province, China. Global and Planetary Change, 143: 175-188.

Yang X H, Jin X B, Guo B B et al., 2015. Research on reconstructing spatial distribution of historical cropland over 300 years in traditional cultivated regions of China. Global \& Planetary Change, 128: 90-102.

Yin C Y, Shi Y S, Wang H F, 2013. Process and characteristics of boundary expansion of built-up area of Shanghai City since the late Qing dynasty. Progress in Geography, 32(12): 1793-1803. (in Chinese)

Zhao E X, 1976. Draft of History of Qing Dynasty. Taipei: Zhonghua Book Company. (in Chinese)

Zhao Q C, 1941. Geography History Table of Qing Dynasty. Beijing: Zhonghua Book Company. (in Chinese)

Zheng B, 2011. Researches on rural residential areas and variation characters of housing construction [D]. Wuhan: China University of Geosciences. (in Chinese)

Zhou G H, He Y H, Tang C L et al., 2013. Dynamic mechanism and present situation of rural settlement evolution in China. Journal of Geographical Sciences, 23(3): 513-524.

Zhu K J, Wang S M, 2008. The research on rural construction movement of Jiangsu during the period of Republic of China. Agricultural History of China, 27(4): 85-92. (in Chinese). 